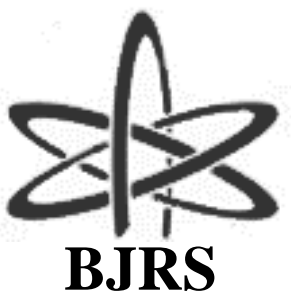

\author{
BRAZILIAN JOURNAL \\ $\mathrm{OF}$ \\ RADIATION SCIENCES \\ 07-02A (2019) 01-09
}

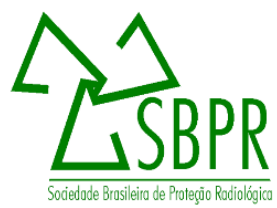

\title{
A comparative study using different resins to determine
}

\section{thorium isotopes}

\author{
M. M. L. Rosa ${ }^{\text {a,b,c; }}$ M. H. T. Taddei ${ }^{\text {b; L. T. V. Cheberle }}$; P. S. C. Silvaa; \\ V. A. Maihara ${ }^{\mathrm{a}}$ \\ ${ }^{a}$ Instituto de Pesquisas Energéticas e Nucleares (IPEN / CNEN - SP) /www.ipen.br/Centro do Reator de Pesquisa \\ $(C R P q)$, 05508-000, São Paulo, SP, Brazil \\ ${ }^{b}$ Comissão Nacional de Energia Nuclear / Laboratório de Poços de Caldas (CNEN / LAPOC) / www.cnenpc.gov.br/ \\ Setor de Radiometria, 37719-005, Poços de Caldas, MG, Brazil \\ ${ }^{c}$ Ambientis Radioproteção /www.ambientis.com.br/Laboratório de Radiometria, 06429-200, Barueri, SP, Brazil \\ my_linhares@yahoo.com.br
}

\begin{abstract}
Thorium is a naturally occurring radioactive element that is widely distributed in the crust of the Earth. This element is very common in mineral formations in regions with high levels of natural radioactivity, therefore, its determination in environmental samples is important. Thorium isotopes $\left({ }^{228} \mathrm{Th},{ }^{230} \mathrm{Th}\right.$, and $\left.{ }^{232} \mathrm{Th}\right)$ were determined in a reference material, the IAEA Soil 327 sample, to validate the two methods, these isotopes were also analyzed in two groups of food samples, employing these different resins (ion exchange and chromatographic). The initial preparation with acid dissolution is the same to both, in the first method is used anion exchange resin (DOWEX 1 2 2) and electrodeposition in silver planchets. And in the second method is used a specific chromatographic resin (TEVA) and cerium fluoride microprecipitation. At the end both analyses are quantified by alpha spectrometry. The two methods the results obtained were satisfactory for the reference material used, with relative error of less than $4 \%$ for ${ }^{228} \mathrm{Th}{ }^{230} \mathrm{Th}$, and ${ }^{232} \mathrm{Th}$. The analysis of variance for samples foods analyzed seen to be no significant difference between the methods used for thorium isotopes determination. The main differences found between methods were spectrums resolutions, time and cost of analysis.
\end{abstract}

Keywords: thorium isotopes, electrodeposition, microprecipitation.

ISSN: 2319-0612

Accept Submission: 2019-01-19 


\section{INTRODUCTION}

Thorium is a radioactive element that occurs naturally in low concentrations in the Earth's crust. In nature, almost all thorium is thorium-232, although several additional isotopes can be present in small amounts. Of the 26 known isotopes of thorium, only 12 have half-lives greater than one second, and of these only 3 have half-lives sufficiently long to warrant a concern [1].

The most important thorium isotopes are ${ }^{232} \mathrm{Th}$ and ${ }^{228} \mathrm{Th}$ of the natural thorium series and ${ }^{234} \mathrm{Th}$ and ${ }^{230} \mathrm{Th}$ which are decay products of natural uranium series, these isotopes are the most important because are alpha emitters that feature radiotoxicity and long half-life [2].

Thorium is generally a health hazard only if it is taken into the body. External gamma exposure is not a major concern because thorium emits only a small amount of gamma radiation [1].

The longer-lived naturally occurring isotopes of thorium are all alpha emitters, so the alpha spectrometry technique can be used to quantify them directly [3].

The electrodeposition is very used on the preparation of thorium samples. Electrodeposition is one of more possibilities for application of electro-gravimetric methods to determine of some trace amount radionuclides [4].

The cerium fluoride micro-precipitation method provides a quicker and simpler way of preparing the alpha count sample, an alternative method for alpha counting instead of electrodeposition. [5]. The method for the determination of actinides and strontium in samples has been developed at the Savannah River Site Environmental Lab (Aiken, SC, USA) that could be used in emergency response situations. The method utilizes a rapid acid digestion method and a streamlined column separation process with stacked TEVA, TRU and Sr resin cartridges. Alpha emitters were prepared using cerium fluoride microprecipitation for counting by alpha spectrometry [6].

Quantitative methods for the determination of actinides have been developed for environmental samples. The procedures include aggressive dissolution, separation by anion-exchange resin, separation and purification by extraction chromatography (e.g., TRU, TEVA and UTEVA resins). Anion-exchange has proved to be a strong tool to treat large volume samples, and extraction chromatography shows an excellent selectivity and reduction of the amounts of acids [7]. 
In this study thorium isotopes, ${ }^{228} \mathrm{Th},{ }^{230} \mathrm{Th}$, and ${ }^{232} \mathrm{Th}$, were determined in a reference material, the IAEA Soil 327 sample [8], to validate the two methods. These isotopes were also analyzed in two groups of food samples belonging to the diet of the population of a city in southeastern Brazil, using electrodeposition in silver planchets for one group and cerium fluoride microprecipitation for the other group.

\section{MATERIALS AND METHODS}

The Reference Material IAEA- Soil 327 was analyzed to compare the methods using different resins to determine thorium radioisotopes. Approximately $2 \mathrm{~g}$ of sample were dissolved with acids (nitric, perchloric, and hydrofluoric, all acids are used P.A.) for both methods.

The samples of the two analyzed groups were dried at $75^{\circ} \mathrm{C}$ and crushed. Approximately $100 \mathrm{~g}$ of food sample was burnt to obtain ash at $450{ }^{\circ} \mathrm{C}$ for 24 hours in a muffle furnace. After that, the ash samples were dissolved with acids (nitric, and perchloric, both acids are used P.A.). The final solution was evaporated, and the salts are dissolved with $8 \mathrm{M}$ nitric acid and $3 \mathrm{M}$ nitric acid, for groups one and two, in order.

The ${ }^{229}$ Th tracer was added in the sample solution containing thorium to determine the chemical recuperation. For the first method the final solution was evaporated, and the salts dissolved with $8 \mathrm{M}$ nitric acid for determination using anion exchange resin (DOWEX 1x2) and electrodeposition. For the other method, the salts were dissolved with $3 \mathrm{M}$ nitric acid and the determination of Th radioisotopes were done using the specific chromatographic resin (TEVA) and microprecipitation.

Method 1: Anion exchange resin (DOWEX 1x2) and electrodeposition - Th radiochemical separation was carried out using Dowex $1 \times 2$ anion exchange resin pre-conditioned with $8 \mathrm{M}$ nitric acid. The sample in nitric media was percolated through anion column Dowex 1x 2 resin. Thorium was retained and eluted with concentrated hydrochloric acid.

The eluted solution was dried on a hot plate and the salts dissolved with the electroplating solution at $\mathrm{pH}$ 2.3. The electroplating solution was prepared using concentrated sulfuric acid, $0.3 \mathrm{M}$ sodium sulfate and deionized water. 
The radioisotopes were electrodeposited on polished silver planchets using an electrical current of 1.0 A for 90 minutes.

Method 2: Chromatographic resin (TEVA) and microprecipitation - Th radiochemical separation was carried out using the TEVA, that is a specific chromatographic resin, pre-conditioned with $3 \mathrm{M}$ nitric acid. The sample in nitric media was percolated through TEVA resin. Thorium was retained and eluted with $6 \mathrm{M} \mathrm{HCl}$ and $9 \mathrm{M} \mathrm{HCl}$.

The eluted fraction was micro-precipitated with a solution of Cerium Fluoride. The precipitate obtained was filtered using a polypropylene filter with $0.1 \mu \mathrm{m}$ porosity and $2.5 \mathrm{~cm}$ diameter and dried under a lamp.

Thorium isotopes quantification - The Th radioisotopes for both methods were analyzed in an Alpha Analyst spectrometer with 12 PIPS (Passivated Implanted Planar Silicon) detectors (counting efficiency 18\%), and Genie 2000/Alpha Analyst spectroscopy systems, from Canberra Industries for 200,000 seconds.

\section{RESULTS AND DISCUSSION}

\subsection{Reference material analysis:}

The activity concentrations of ${ }^{228} \mathrm{Th},{ }^{230} \mathrm{Th}$, and ${ }^{232} \mathrm{Th}$ radioisotopes in the IAEA- Soil 327 obtained after radiochemical separations are presented in the Table 1, the recommended value is showed with 95\% confidence interval.

Table 1: Results for different methods - IAEA-Soil 327.

\begin{tabular}{cccc}
\hline Radionuclide & $\begin{array}{c}\text { Method 1 } \\
\mathbf{B q} / \mathbf{k g}\end{array}$ & $\begin{array}{c}\text { Method 2 } \\
\mathbf{B q} / \mathbf{k g}\end{array}$ & $\begin{array}{c}\text { Recommended } \\
\text { Value } \mathbf{~ B q / k g}\end{array}$ \\
\hline${ }^{\mathbf{2 2 8}} \mathbf{T h}$ & $37.0 \pm 1.7$ & $37.3 \pm 1.6$ & $38.2 \pm 1.0$ \\
${ }^{{ }^{230} \mathbf{T h}}$ & $33.3 \pm 1.5$ & $33.2 \pm 1.6$ & $34.1 \pm 1.7$ \\
${ }^{{ }^{232} \mathbf{T h}}$ & $37.6 \pm 1.7$ & $37.2 \pm 1.5$ & $38.7 \pm 1.5$ \\
\hline
\end{tabular}


The relative error (RE) was used as a measure of precision. Is the ratio of the absolute error of a measurement to the measurement being taken. In other words, this type of error is relative to the size of the item being measured RE is expressed as a percentage and has no units [9]. The RE for analysis are present in the Table 2.

By the results obtained these methodologies can be considered effective and efficient, since they presented relative error less than or equal to $4 \%$.

Table 2: The relative error.

\begin{tabular}{ccc}
\hline Radionuclide & $\begin{array}{c}\text { RE (\%) } \\
\text { Method 1 }\end{array}$ & $\begin{array}{c}\text { RE (\%) } \\
\text { Method 2 }\end{array}$ \\
\hline${ }^{{ }^{228} \text { Th }}$ & 3.14 & 2.36 \\
${ }^{{ }^{230} \text { Th }}$ & 2.35 & 2.69 \\
${ }^{{ }^{232} \text { Th }}$ & 2.84 & 3.86 \\
\hline
\end{tabular}

\subsection{Foods samples analyzed:}

The activity concentrations of ${ }^{228} \mathrm{Th},{ }^{230} \mathrm{Th}$ and ${ }^{232} \mathrm{Th}$ radioisotopes in both groups of food samples obtained after radiochemical separations are presented in the Table 3.

The chemical recovery of method 1 (anion exchange resin and electrodeposition) ranged from 62 and $100 \%$ and for method 2 (chromatographic resin and microprecipitation) between 52 and 100\%. The chemical recovery analysis was realized with the addition ${ }^{229} \mathrm{Th}$ tracer source $0.035 \mathrm{~Bq}$ for sample.

Some samples have very different activity concentration values for the same isotope, for example nuts and seeds group, this can be explained because the samples of the groups were collected in different places. 
Table 3: Results for different methods - foods samples analyzed

\begin{tabular}{|c|c|c|c|c|c|c|}
\hline \multirow{2}{*}{$\begin{array}{r}\text { Food } \\
\text { Samples }\end{array}$} & \multicolumn{3}{|c|}{ Method 1 (Bq/kg) } & \multicolumn{3}{|c|}{ Method $2(\mathrm{~Bq} / \mathrm{kg})$} \\
\hline & ${ }^{228} \mathrm{Th}$ & ${ }^{230} \mathrm{Th}$ & ${ }^{232} \mathrm{Th}$ & ${ }^{228} \mathrm{Th}$ & ${ }^{230} \mathrm{Th}$ & ${ }^{232} \mathrm{Th}$ \\
\hline Cereal & $0.12 \pm 0.01$ & $<0.01$ & $<0.01$ & $0.19 \pm 0.01$ & $<0.01$ & $<0.01$ \\
\hline Beans & $0.35 \pm 0.02$ & $<0.01$ & $<0.01$ & $0.59 \pm 0.02$ & $<0.01$ & $0.03 \pm 0.01$ \\
\hline Vegetables & $0.37 \pm 0.02$ & $<0.01$ & $<0.01$ & $0.68 \pm 0.04$ & $0.04 \pm 0.05$ & $0.01 \pm 0.01$ \\
\hline Fruits & $0.14 \pm 0.01$ & $<0.01$ & $0.01 \pm 0.003$ & $0.21 \pm 0.01$ & $<0.01$ & $0.01 \pm 0.01$ \\
\hline Nuts and Seeds & $4.05 \pm 0.15$ & $0.03 \pm 0.01$ & $0.03 \pm 0.01$ & $0.87 \pm 0.12$ & $0.01 \pm 0.003$ & $<0.01$ \\
\hline $\begin{array}{l}\text { Flours, Pasta and } \\
\text { Bakery Products }\end{array}$ & $0.15 \pm 0.02$ & $0.01 \pm 0.004$ & $0.01 \pm 0.004$ & $0.39 \pm 0.02$ & $0.06 \pm 0.01$ & $<0.01$ \\
\hline Cakes and Biscuits & $0.30 \pm 0.02$ & $0.06 \pm 0.01$ & $0.06 \pm 0.01$ & $0.29 \pm 0.44$ & $<0.01$ & $<0.01$ \\
\hline Cattle Meat (beef) & $0.10 \pm 0.01$ & $<0.01$ & $<0.01$ & $0.40 \pm 0.06$ & $0.07 \pm 0.01$ & $0.02 \pm 0.01$ \\
\hline Pork & $0.04 \pm 0.01$ & $<0.01$ & $<0.01$ & $0.36 \pm 0.04$ & $0.04 \pm 0.01$ & $0.01 \pm 0.01$ \\
\hline Poultry & $0.03 \pm 0.01$ & $<0.01$ & $<0.01$ & $0.19 \pm 0.01$ & $0.01 \pm 0.003$ & $<0.01$ \\
\hline Fish & $0.12 \pm 0.01$ & $0.03 \pm 0.005$ & $0.03 \pm 0.004$ & $0.30 \pm 0.04$ & $<0.01$ & $0.02 \pm 0.01$ \\
\hline $\begin{array}{c}\text { Industrialized } \\
\text { Meat and Offal }\end{array}$ & $0.25 \pm 0.01$ & $<0.01$ & $<0.01$ & $0.37 \pm 0.05$ & $0.05 \pm 0.01$ & $0.01 \pm 0.01$ \\
\hline Eggs & $0.08 \pm 0.01$ & $<0.01$ & $<0.01$ & $0.50 \pm 0.08$ & $<0.01$ & $<0.01$ \\
\hline Dairy Products & $0.05 \pm 0.01$ & $<0.01$ & $<0.01$ & $0.87 \pm 0.17$ & $0.04 \pm 0.01$ & $<0.01$ \\
\hline Sweets & $0.07 \pm 0.01$ & $0.02 \pm 0.01$ & $<0.01$ & $0.77 \pm 0.02$ & $0.05 \pm 0.01$ & $0.10 \pm 0.01$ \\
\hline Oils and Fats & $0.31 \pm 0.05$ & $<0.01$ & $<0.01$ & $0.45 \pm 0.07$ & $0.02 \pm 0.02$ & $0.02 \pm 0.01$ \\
\hline Beverages & $0.03 \pm 0.01$ & $<0.01$ & $<0.01$ & $0.03 \pm 0.01$ & $<0.01$ & $<0.01$ \\
\hline $\begin{array}{l}\text { Industrialized } \\
\text { Products }\end{array}$ & $0.07 \pm 0.01$ & $<0.01$ & $<0.01$ & $0.57 \pm 0.02$ & $0.03 \pm 0.003$ & $<0.01$ \\
\hline Salt & $0.26 \pm 0.04$ & $<0.01$ & $<0.01$ & $0.21 \pm 0.04$ & $<0.01$ & $<0.01$ \\
\hline Water & $<0.01$ & $<0.01$ & $<0.01$ & $<0.01$ & $<0.01$ & $<0.01$ \\
\hline
\end{tabular}


The two methods employed in this study for thorium isotopes determination in food samples belonging to the diet of the population of a city in southeastern Brazil, were compared by applying analysis of variance. This test presented, a statistical probability of approximately $95 \%$, meaning that both methods fit model well. The analysis of variance presents a $p$-value of 0.1204 , greater than 0.05. Thus, statistically speaking, there seen to be no significant difference between the methods used for thorium isotopes determination.

The main differences found between the method using exchange resin (DOWEX 1x2) and electrodeposition, and the specific chromatographic resin (TEVA) and microprecipitation are spectrum resolutions. The microprecipitation showed a spectrum with not good resolution.

However, the time and cost of analysis using the specific chromatographic resin (TEVA) and microprecipitation is smaller and less expensive about the method exchange resin (DOWEX 1x2) and electrodeposition.

Typically, the method using TEVA resin takes two to three days while the other method takes up to six days. Besides the method using the ion exchange resin spends larger amounts of acids due to the large volume of the resin and at the end of the analysis still has the value of the silver planchets for electrodeposition which makes it more expensive.

\section{CONCLUSION}

Although exchange resin (DOWEX 1x2) and electrodeposition technique requires a refined chemical process in relation to the chromatographic resin (TEVA) and microprecipitation technique, that requires little treatment of the sample, both methods presented high precision and good accuracy in the results. The method 2 is better than method 1, about as the such as time and the use of acids, generating waste minimum in the analysis. After the various analyzes in this study, it was possible to conclude that both methods are suitable for determination of thorium radioisotopes. 


\section{ACKNOWLEDGMENT}

The authors would like to thank the National Nuclear Energy Commission - Poços de Caldas Laboratory (CNEN/LAPOC) and the Institute of Energy and Nuclear Research (IPEN/CNEN) and the CNPq.

\section{REFERENCES}

1. MASSARI, S.; RUBERTI, M. Rare earth elements as critical raw materials: Focus on international markets and future strategies. Resources Policy, v. 38 (1), pp. 36-43, 2013.

2. LAURIA, D. C.; ROCHEDO, E. R. R.; GODOY, M. L. D. P.; SANTOS, E. E.; HACON, S. S. Naturally occurring radionuclides in food and drinking water from a thorium-rich area. $\mathbf{J}$. Radiation and Environmental Biophysics, v. 51, p. 367-374, 2012.

3. LIESER, K. H. Nuclear Chemistry and Radiochemistry - Fundamentals and Applications, $2^{\text {nd }}$ ed. Darmstadt, Wiley-VCH, 2001.

4. MÁTEL, L.; HOLÝ, K. Prírodná rádioaktivita V. Chemické a rádiochemické kontaminanty životného prostredia, Omega Info, Bratislava, 2006.

5. MAXWELL S. Rapid analysis of emergency urine and water samples. Journal of Radioanalytical and Nuclear Chemistry, v. 275 (3), p. 497-502, 2008.

6. MAXWELL, S.; CULLIGAN, B. K.; NOYES, G. W. Rapid separation method for actinides in emergency air filter samples. Applied Radiation and Isotopes, v. 68(12), p. 2125-2131, 2010.

7. LEE, S. H.; LA ROSA, J.; GASTAUD, J.; POVINEC, P. P. The development of sequential separation methods for the analysis of actinides in sediments and biological materials using anion-exchange resins and extraction chromatography. Journal of Radioanalytical and Nuclear Chemistry, v. 263 (2), p. 419-425, 2005. 
8. IAEA - International Atomic Energy Agency. Reference Sheet: Reference Material IAEA-327 Radionuclides in Soil. Vienna, 2001.

9. INMETRO. DOQ-CGCRE-008, Orientações sobre validação de métodos de ensaios químicos. Rio de Janeiro, 2003. 